\title{
Hydrodynamics of a small trained tidal inlet (Currumbin Creek, Australia)
}

\author{
S. Shaeri ${ }^{1}$, R. B. Tomlinson ${ }^{1}$, A. Etemad-Shahidi ${ }^{2}$, D. Strauss ${ }^{1}$, and L. P. Hughes ${ }^{1}$ \\ ${ }^{1}$ Griffith Centre for Coastal Management, Griffith University, Australia \\ ${ }^{2}$ School of Engineering, Gold Coast Campus, Griffith University, Australia
}

Correspondence to: S. Shaeri (saeed.shaeri@griffithuni.edu.au)

Received: 6 November 2013 - Revised: 17 January 2014 - Accepted: 28 January 2014 - Published: 1 April 2014

\begin{abstract}
Small tidal inlets are important features of coastal areas, in terms of provision of access from a back barrier water-body to the ocean as well as periodic circulation of fresh nutrients for the local ecology. Usually, dimensional and geometrical characteristics contribute significantly to morphological stability or instability of a particular inlet and necessitate an individual investigation of any desired location. In other words, generalized usage of previous empirical and experimental research of a different position can hardly be used for other places. In this regard, one of the powerful tools to understand the physical processes of a particular region is to collect as much field data as possible. Such a dataset is used to further analyse and explore the governing processes and can also be used for building a numerical computer model for supplementary studies.

In this research, the results of a comprehensive field measurement at Currumbin Creek, Queensland, Australia are presented. This study is part of broader research to investigate the long term evolution of the Currumbin entrance and its adjacent beaches. Currently, an annual dredging campaign is needed to reduce the risk of flooding due to excess rainfall inundations and to maintain water quality.

The majority of data were collected over a three month period consistent with the time of the 2012 dredging operation. However, due to the loss of some instrumentation, data collection for some of the parameters was repeated till the middle of May 2013. All collected data included: (1) nearshore waves and tide; (2) creek tidal variation; (3) creek flow discharge and velocity; (4) bathymetric survey of the creek; (5) beach profile evolution survey; and (6) sediment sampling. The measurement showed that the creek entrance is tidally dominated, with flood events having a major role in sediment transport into the creek. The nearshore stations' wave data il-
\end{abstract}

lustrated the marginal effect of the beach curvature between updrift and downdrift stations. Thus, the historical dataset available from the updrift wave rider buoy will be selected to be used for future numerical modelling. Although changes of some beach profiles were comparatively insignificant, the dramatic changes of the profile lines nearby the inlet channel and also rapid bathymetric change of the flood shoal following the dredging completion are valuable information to better calibrate and interpret a local sediment modelling study for the next phase. Essentially, this evaluation needs to be considered for proposing any alternative maintenance activities.

\section{Introduction}

Tidal inlets have significant importance for residents of coastal areas for safe navigation, since inlets provide water exchange to the back barrier water bodies as well. However, seasonal or partial closure of the entrance and/or insufficient water depth adjacent to it, are possibly two major issues for small tidal inlets which limit the thorough usage of small inlets. Although, a large proportion of existing studies have dealt with wide (large) inlets or inlets with large backbarriers (with a large volume of tidal prism), generally speaking, small inlets have different environmental characteristics than large ones. Therefore, it is not an accurate practice to apply the outcome derived from wide/large inlets to small inlets and so there are still specific needs to separately investigate small inlets.

One of the appropriate approaches for understanding the hydrodynamics of small inlets is to collect data from that particular area. Such data can provide an insight to understand 


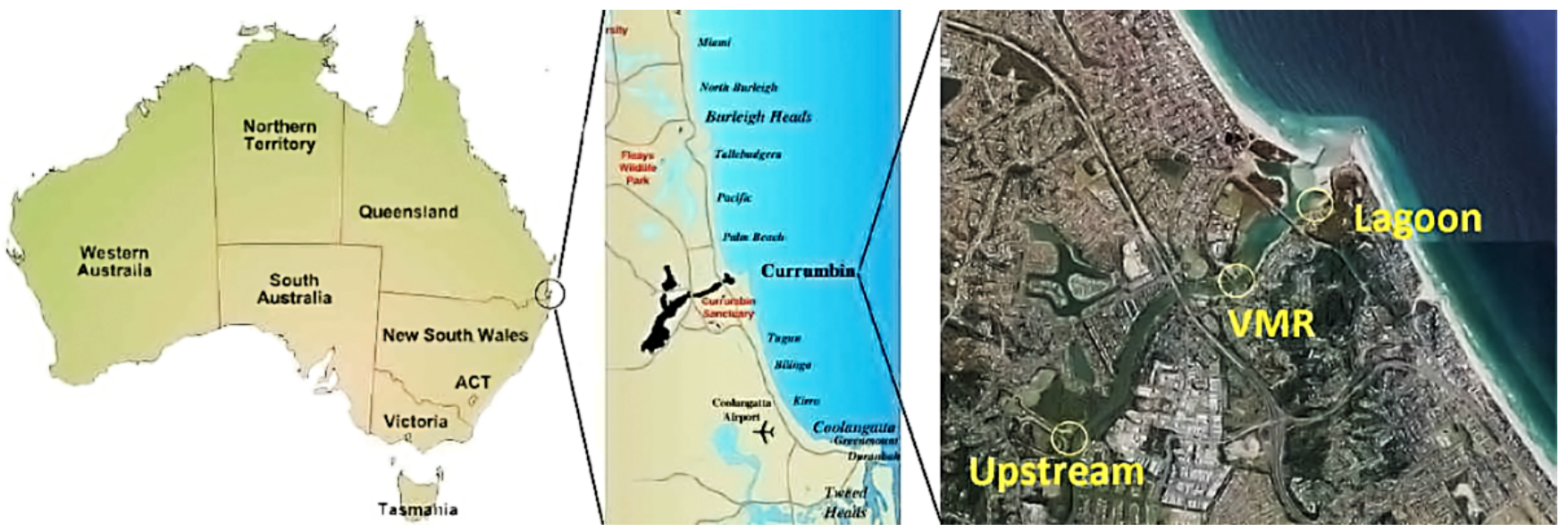

Fig. 1. Study Area, Currumbin Creek and approximate location of the creek stations.

better the complicated physics of these dynamic environments. This paper is part of a study of long term morphological evolution of a small tidal inlet. It examines data obtained from a comprehensive field campaign over 4 consecutive months of dramatic change at Currumbin Creek. In future studies, such data sets are also beneficial to better calibrate desirable computer models which are suitable to investigate alternative design proposals.

\section{Study area}

Currumbin Creek is a small estuary, located in the Gold Coast region of south-eastern Queensland, Australia (28.127 S, 153.484E) (Fig. 1). Gold Coast beaches are exposed to a variety of different seasonal wave regimes (Castelle et al. 2007). South to southeast high energy swells of the winter and spring play the major role in the net northward sediment transport pattern. Northeast to east (often potentially destructive) swells may occur during Nov. to Apr. from tropical cyclones moving south. Additionally, East Coast Lows (ECL) may occur throughout the year. These are intense storms which are more common from Mar. till Jul. and which produce strong winds from the northeast to southeast generating high energy swells (Callaghan et al. 2011). The mean tidal range is approximately $1 \mathrm{~m}$ and is predominantly semi-diurnal (Shaeri et al. 2013c). In addition, the spring tidal range and neap tidal range are about $1.8 \mathrm{~m}$ and $0.6 \mathrm{~m}$, respectively.

Due to the importance of this creek for the local community, a jettied training wall was built on its southern beach in early 1970s' to control the net northward movement of sediments and also deposition of sediment at the inlet entrance. Subsequently, another jetty was built on the northern beach with the intention to control downdrift erosion. Nevertheless, the shallowness of the entrance and partial closing of the creek are currently a safety issue (D'Agata et al.,
2001). Annual dredging is still needed to reduce the risk of flooding due to excess rainfall inundations and to maintain water quality as well as to reallocate sediments to the adjacent downdrift beach. However, it is also observed that previous dredging campaigns have been marginally ineffective (D'Agata et al., 2002). Basically, the dredging hole quickly filled following each previous campaign.

\section{Design of field measurements}

Knowing about the physics and dynamics of the area of interest is an essential part for accurate design of field investigations. Castelle et al. (2007) implemented numerical analyses of the creek and surrounding beaches and described the effect of constructed jetties on overall longshore transport and also on sand by-passing the inlet. They found that such changes resulted in transverse circulation patterns downdrift of the inlet entrance, which also contributes to the inlet infilling processes. However, as these researchers were mainly interested in knowing about the inlet variation, they have used a simplified simulation domain for the creek itself, which did not present the actual geometry and bathymetry. Thus, the tidal current and prism inside the creek were estimated.

Considering the importance of the creek upstream in terms of: (1) the influence of above-normal rainfall on production of an extreme creek discharge; (2) the attenuation of tidal current as a result of creek vegetation (roughness); and also (3) the effect of the creek geometry on the hydraulics of its stream, indicates that data from the creek upstream is essential. Moreover, as the influence of the entrance is also important, data offshore from the entrance is necessary as well.

Based on these reasons and to investigate the governing physical processes, a course of field measurements was conducted, before, during and after the 2012 dredging which included: (1) nearshore wave and tide; (2) creek tidal variation; (3) creek flow discharge and velocity; (5) bathymetric survey 


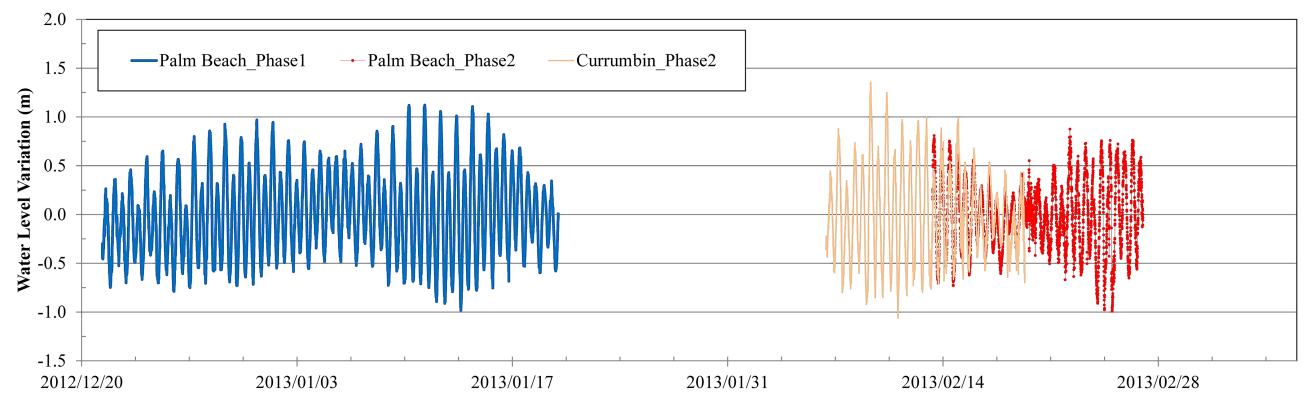

Fig. 2. Water level variations at the nearshore wave recording stations.

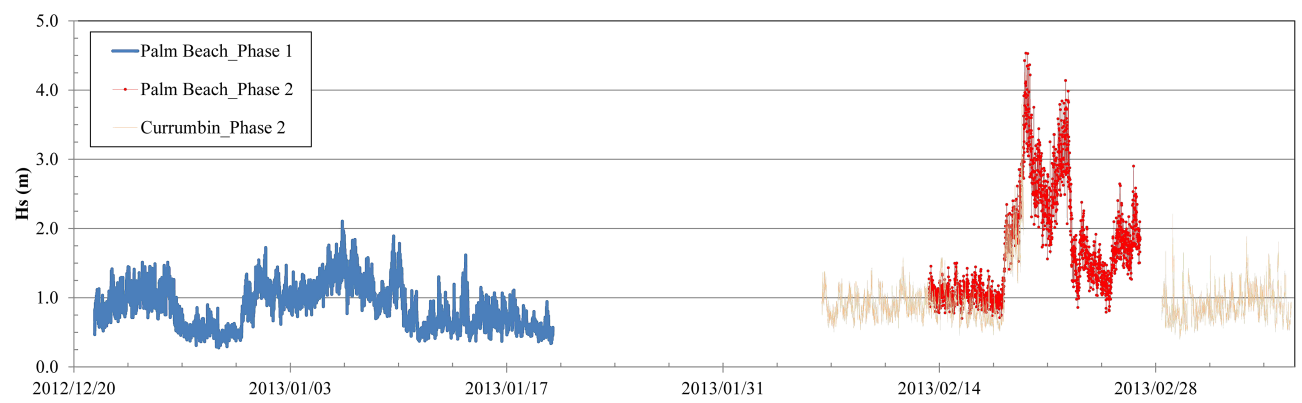

Fig. 3. Significant wave height at the nearshore wave recording stations.

of the creek; (6) beach profile evolution survey; and (6) sediment sampling.

\section{Data collection}

As described earlier, based on the time of 2012 dredging campaign (which was accomplished from 10 October to 30 November), the following measurements were conducted.

\subsection{Nearshore wave and tide measurements}

Nearshore wave and tide data were recorded by using bottom-situated RBR data recorders (Shaeri et al., 2013c). This was done in 2 separate stages and in 2 different locations (Palm Beach and Currumbin, see Fig. 1), all at a depth of about $7 \mathrm{~m}$ (LAT). The first campaign was conducted from 21 December 2012 to 20 January 2013 and the second from 6 February 2013 to 8 March 2013. Figure 2 shows the water level variations. Variations of the significant wave height are also shown in Fig. 3.

\subsection{Creek tide variations}

Tidal variation inside the creek was measured at 3 different stations (Fig. 1), namely: (1) Upstream (3.5 km from the entrance); (2) VMR (1.5 km from the entrance); and (3) the Lagoon (200 $\mathrm{m}$ from the entrance) (Shaeri et al., 2013a). This data was collected by means of bottom-situated RBRs from 8 April 2013 to 19 May 2013. For simplicity of comparison, only the extreme daily water levels were extracted from the data set. Figure 4 shows the water level variations of the creek stations relative to the LAT.

\subsection{Creek flow and discharge variations}

The creek flow and discharge data were also measured in the vicinity of the VMR station. Data were collected on 3 different days of 7 December 2012 (at the time of the Neap tide); 9 December 2012 (at the time of the second Neap tide of the month); and 13 December 2012 (at the time of the Spring tide). Collecting data at the neap and spring tides usually provides the extreme values for the creek discharge in comparison to other days of the lunar month. The other reason for the chosen dates is the fact that these dates were at the time of the annual summer extreme tidal range of the year (known as the king tide). Hence, it is expected that the collected flow and discharge data well represent of the annual extreme of these events. For this data collection, the common method of river cross-profiling was chosen and a boat-mounted Teledyne RDI was used.

Figure 5 shows the variation of the creek discharge and the average flow velocity at the time of discharge measurements. In these graphs, for simplicity of comparison, the actual date of data collection is not presented. Also, the negative figures denote a flood current (toward the creek upstream).

\subsection{Creek and entrance bathymetric survey}

It was expected that the lagoon area would respond to the changes resulting from the dredging activity. Therefore, in 


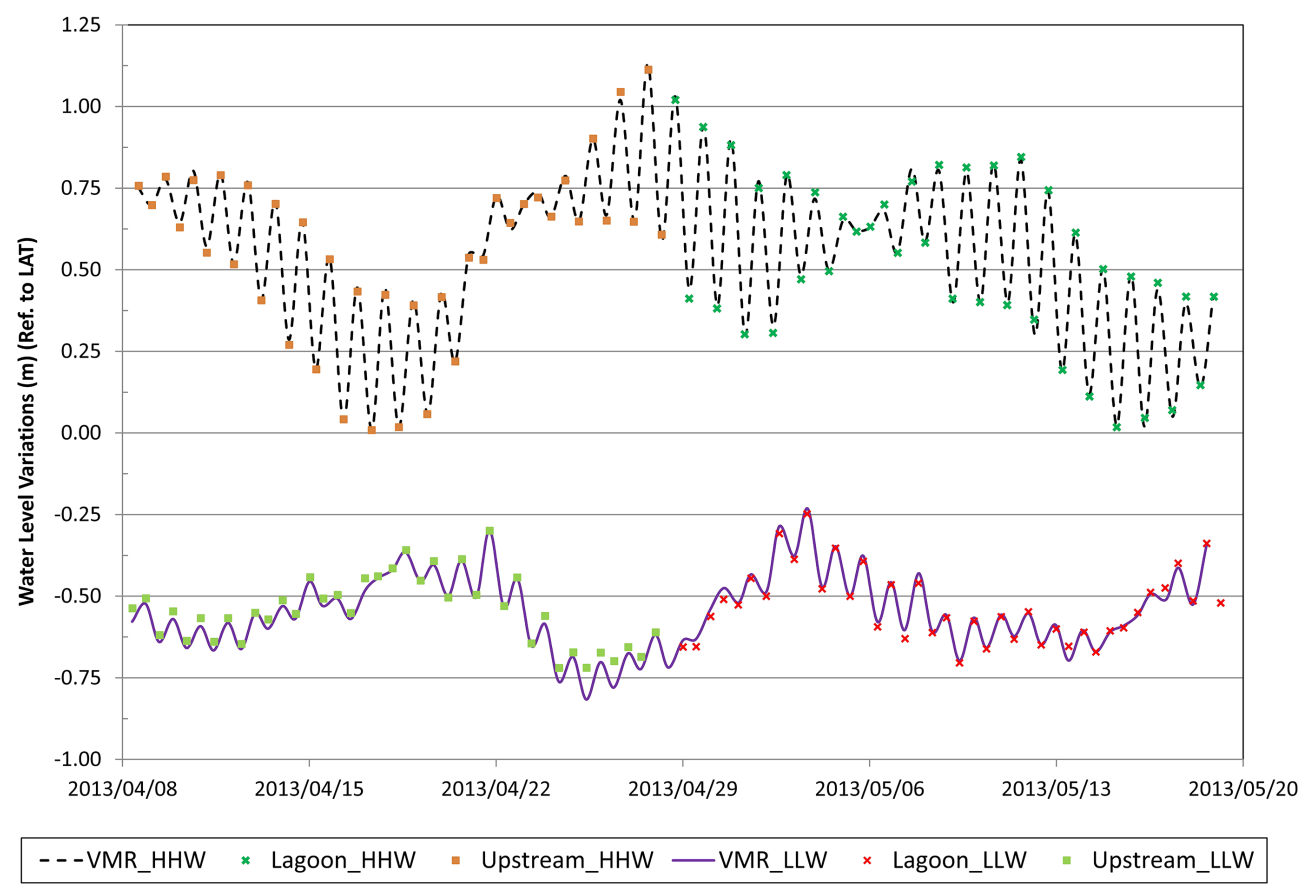

Fig. 4. Daily extreme water levels at the creek's stations for highest high water (HHW) and lowest low water (LLW).

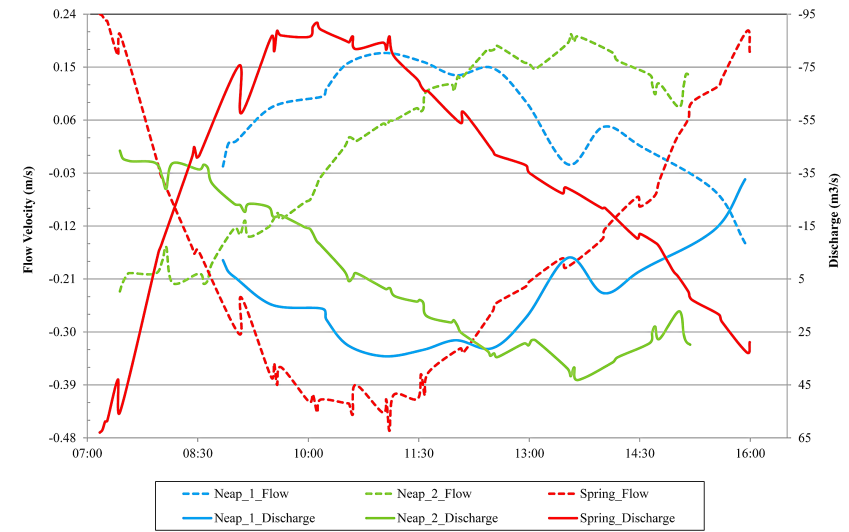

Fig. 5. Discharge and flow velocity measurements across the creek width at VMR station.

order to evaluate the spatial changes of the location of the dredging hole, the flood shoal and also the creek itself, a series of bathymetric surveys was designed to be conducted before, during and after the 2012 dredging. Figure 6 shows three consecutive bathymetric surveys which relate to the immediate end of the dredging campaign until three months thereafter.

\subsection{Beach profile evolution survey}

In order to investigate the extent of shoreline change around the survey area, a series of beach profile measurements were carried out (Shaeri et al., 2013b, 2014). This data collection started prior to the commencement of the dredging operation inside the creek and continued up to the end of that work. Basically, data were collected on a weekly basis from particular locations all along the northern and southern beaches of the inlet entrance, as well as all around the inlet channel and the lagoon area. Figure 7 shows the approximate locations of the beach-profile lines. The area was divided into 141 profile lines and 16 weeks of elevation survey have been carried out for the entire region. This period started from 2 December 2012 (in week 1) and continued to 10 March 2013 (in week16). For simplicity, 10 selected results are presented in Figs. 8 and 9. Note that in week 13 (from 11 February 2013), there were intense storm events which influenced the outcome of surveys (cf. Sect. 5.1).

\subsection{Sediment sampling}

In order to achieve an approximate estimate of the grain size of the creek's bottom layer sediment, 16 sediment samples were collected from the area. Figure 7 shows the approximate locations of these samples. Sediment size analysis has also been carried out for the collected samples to find the characteristic sediment sizes of $\mathrm{D}_{15}, \mathrm{D}_{50}$ and $\mathrm{D}_{85}$. Furthermore, the dry and wet bulk densities have also been identified for a better comparison between samples. 


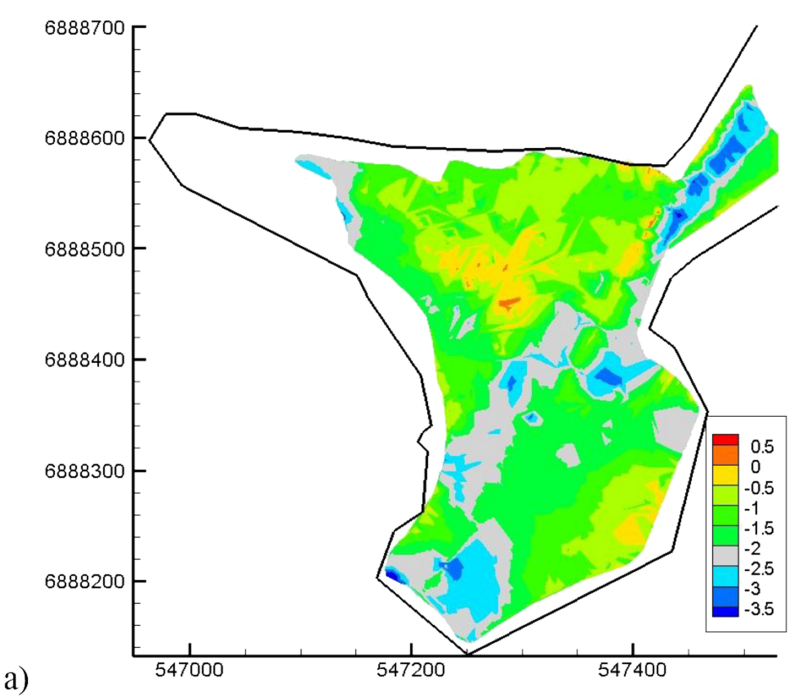

a)

\section{Data analysis and results}

\subsection{Nearshore wave and tide measurements}

The graphs in Fig. 2 show a semidiurnal tidal variation with a range of about $2 \mathrm{~m}$. Also, for about a week during Phase 2 of this data collection, both devices recorded simultaneously and, as can be seen, the tidal levels and cycles were nearly identical.

During the first phase of this data collection, the sea state was generally calm with wave heights being mainly around $1 \mathrm{~m}$ (Fig. 3). However, during the second phase, the devices recorded very intense storms (in week 13), with significant wave height reaching around $4.5 \mathrm{~m}$. Unfortunately, the device at the Currumbin Station did not record any data during the heaviest days of the stormy conditions. However, as with the water level data, both devices recorded almost the same wave regime during the week before the February 2013 storms.

\subsection{Creek tide variations}

The graphs in Fig. 4 show that the recorded water levels are harmonic and show that the creek stream is governed by a tidal flow. All three stations (upstream, middle (VMR) and downstream (Lagoon)) can also be observed to have roughly identical recordings, both for the high and low water data. The tidal range was about $2 \mathrm{~m}$. As there is no abrupt change (phase shift) in the graphs, it can further be concluded that there is no influence from the freshwater discharge.

\subsection{Creek flow and discharge variations}

As can be seen in Fig. 5 the absolute maximum discharge at the time of spring flood (the red line) is about $95 \mathrm{~m}^{3} \mathrm{~s}^{-1}$ while the absolute amount of maximum discharge at the time of neap ebb (the green line) falls just below $45 \mathrm{~m}^{3} \mathrm{~s}^{-1}$. This is an indication of the fact that the creek is flood dominated. Comparing the creek flow velocities also reveals that absolute maximum flow speed at the time of spring flood (the red dotted line) is about $0.47 \mathrm{~m} \mathrm{~s}^{-1}$ while the maximum flow speed at the time of neap ebb (the green dotted line) is almost $0.23 \mathrm{~m} \mathrm{~s}^{-1}$. Therefore, this also indicate the dominance of flood events inside the creek.

\subsection{Creek and entrance bathymetric survey}

There are some identifiable changes of the bathymetry of the lagoon at the end of the dredging operation relative to the operation's commencement (Fig. 6a comparing to c). More specifically, the extent of the flood shoal shows a shift towards the entrance. Apart from the visual observations that show a hypothetical tendency of sediment movement towards the dredging hole, variations in the red areas (above $+0.5 \mathrm{~m}$ ) also verify the hypothesis. Other parts of the lagoon area were virtually unchanged during the data collection period. 


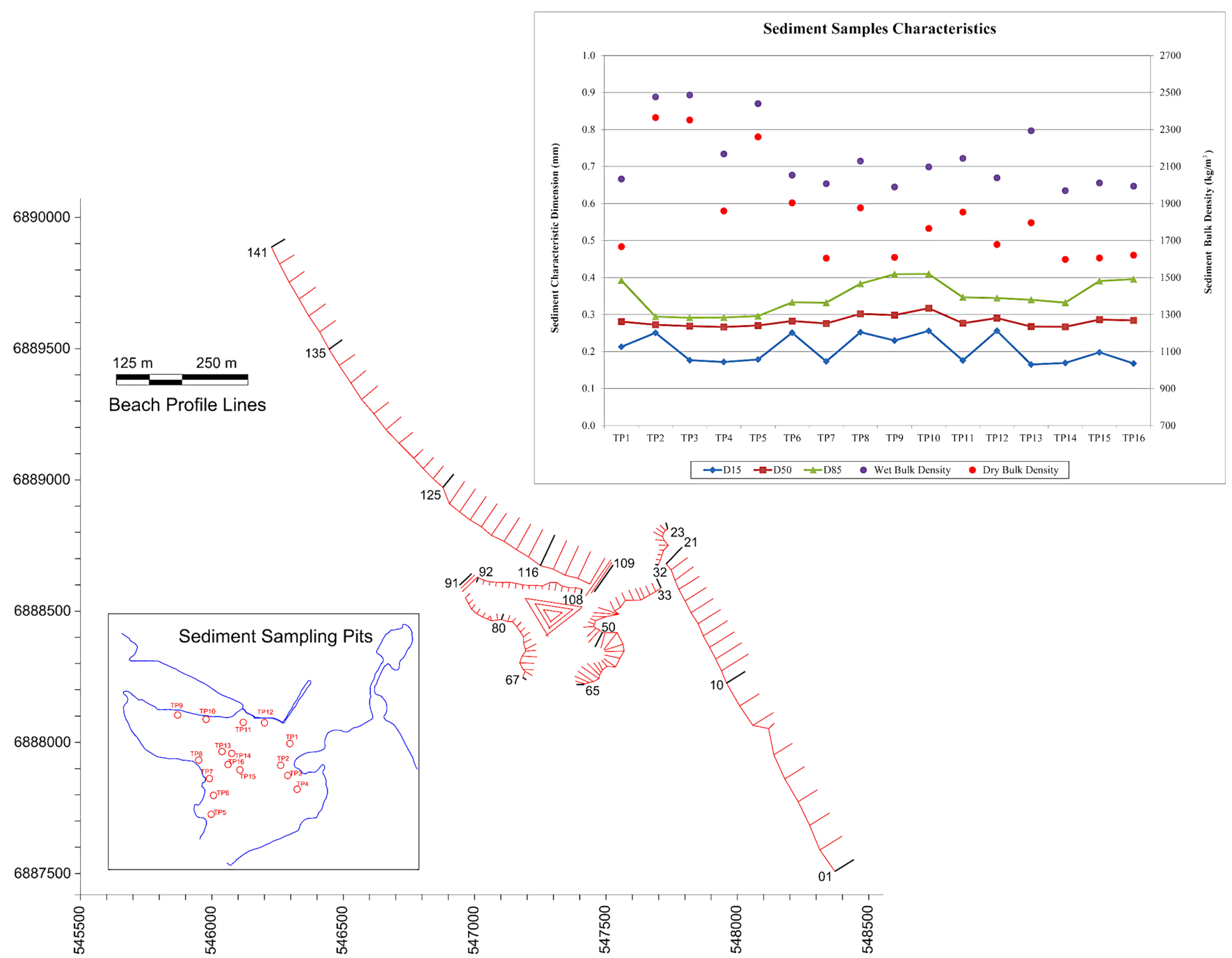

Fig. 7. Location of beach-profile lines in addition to sediment sampling pits locations and characteristics.

\subsection{Beach profile evolution survey}

Most of the beach profile graphs (Figs. 8 and 9) do not show significant changes over the 3 months period (although there are some fluctuations). However, the most important lines are No. 34, 42 and 46 which respectively relate to the entrance, the inlet channel and the lagoon locations. As can be seen, there was a large sediment accumulation in week 10 at Line 34 which disappeared after the storms in week 13. However, the aforementioned sediment movement tendency towards the inlet entrance is clearly distinguishable for lines 42 to the extent that there was about $15 \mathrm{~m}$ movement for the edge of the line between week 9 and week 16. A similar pattern with less intensity is also seen for Line 46.

\subsection{Sediment sampling}

From the sediment graph (Fig. 7) it can be inferred that the sixteen samples are more or less the same in terms of charac- teristic diameters $\left(D_{15}, D_{50}\right.$ and $\left.D_{85}\right)$. Specifically for $D_{50}$ which is mainly used in numerical modelling, the bottom sediment in the area seems very uniformly distributed. However, noticeable changes of wet and dry bulk densities suggest a further investigation to identify possible differences between deposited sediments.

\section{Conclusions}

Field measurements of the Currumbin Creek provided a valuable set of data which will assist with defining the input data and boundary conditions for the numerical modelling phase of the study. This kind of information will aid the calibration/validation of numerical modelling as well, if measured simultaneously. From these measurements, it is concluded that the creek entrance is tidally dominated, with flood events having a major role. Moreover, the data collected from the nearshore stations also showed a strong similarity between 

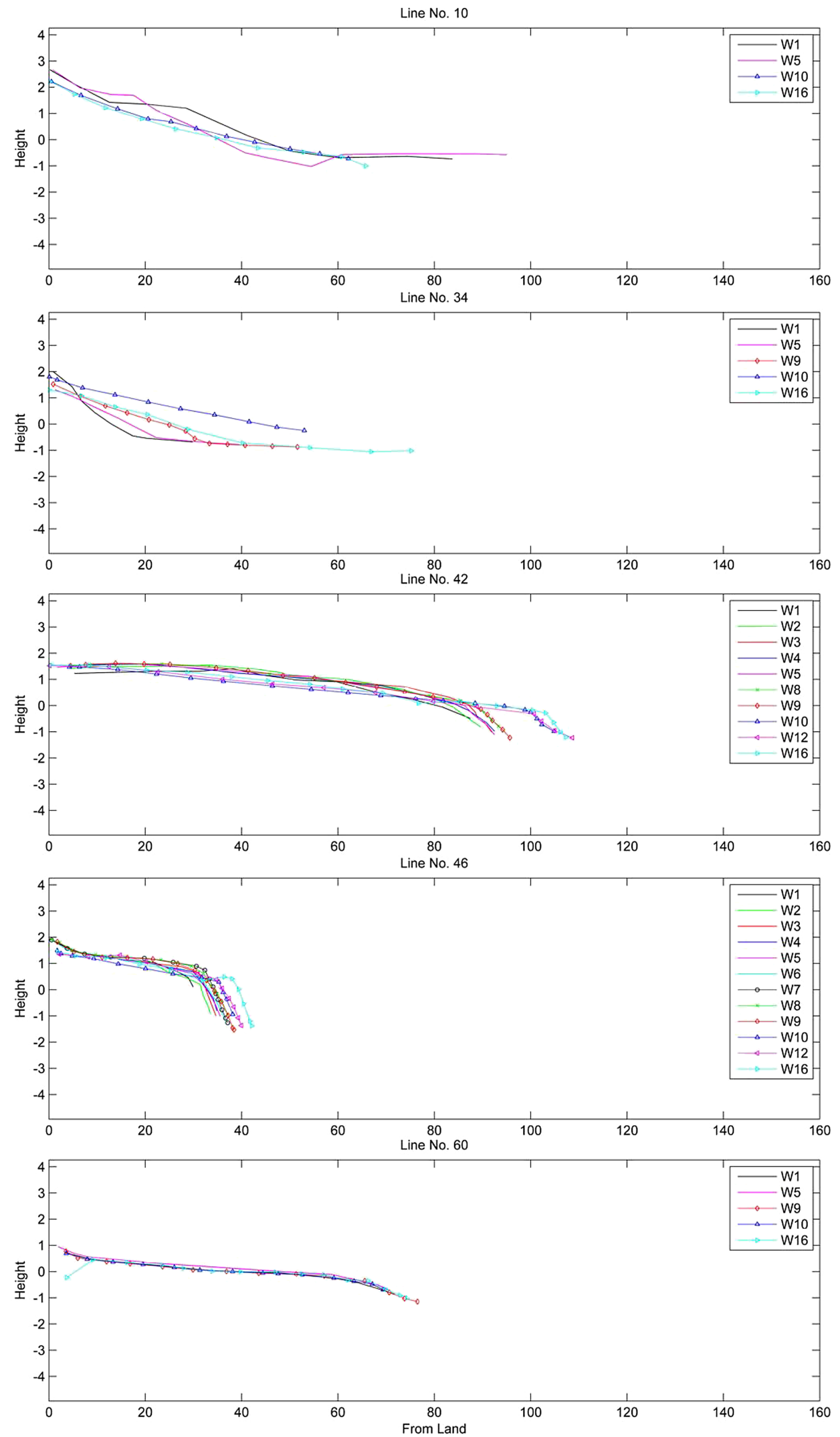

Fig. 8. Survey of the beach profile evolution for Line no. 10, 34, 42, 46 and 60. (All dimensions in meter.) 
Line No. 70
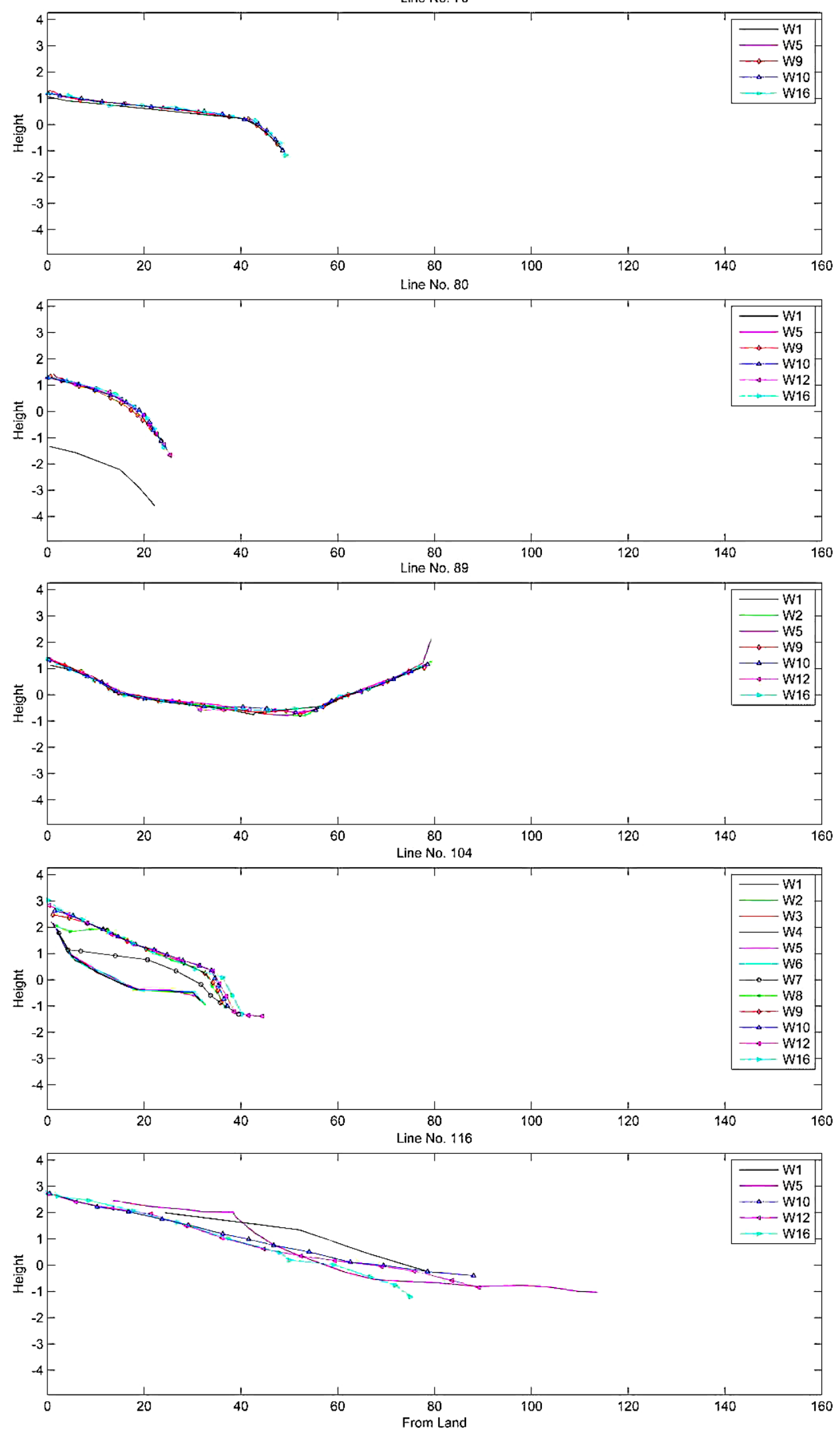

Fig. 9. Survey of the beach profile evolution for Line no. 70, 80, 89, 104 and 116. (All dimensions in meter.) 
the updrift and downdrift stations. Therefore a long term dataset from the updrift wave rider buoy will be used as input data for the model. Also, subtle changes of the beach profile at some locations are considered to be highly important for sediment modelling study and calibration of such a model. In comparison, the rapid change of the flood shoal area, which occurs naturally in response to dredging the bed, is an essential point to consider for proposing any alternative maintenance activities.

Acknowledgements. The work described in this publication was supported by the Griffith Centre for Coastal Management (GCCM) as part of the Gold Coast Shoreline Management Plan (GCSMP). Data was collected by GCCM with financial support from the City of Gold Coast (CoGC).

\section{References}

Callaghan, J. and Power, S. B.: Variability and Decline in the Number of Severe Tropical Cyclones Making Land-Fall over Eastern Australia since the Late Nineteenth Century, Clim. Dynam., 37 , 647-662, 2011.

Castelle, B. O., Bourget, J., Molnar, N., Strauss, D., Deschamps, S., and Tomlinson, R. B.: Dynamics of a wave-dominated tidal inlet and influence on adjacent beaches, Currumbin Creek, Gold Coast, Australia', Coast. Eng., 54, 77-90, 2007.
D'Agata, M. and Tomlinson, R. B.: Discussion of the Dredging of the Internal Delta of Currumbin Estuary and Its Impact on Adjacent Beaches, paper presented to Australasian Port and Harbour Conference (8th: 2001: Gold Coast, Qld.), Barton, A.C.T., 2001.

D'Agata, M. and Mc Grath, J.: The Use of Currumbin Creek as a Sand Reserve: Towards Better Dredging Management, Littoral 2002, 2, 495-501, 2002.

Shaeri, S., Tomlinson, R. B., and Etemad-Shahidi, A.: Beach profile changes around a wave-dominated tidal inlet entrance', 16th Workshop on Physical Processes in Natural Waters (PPNW), Queensland, Australia, July 2013a.

Shaeri, S., Tomlinson, R. B., Etemad-Shahidi, A., and Strauss, D.: The Importance of Accurate Prediction of Tidal-Induced Water Level Variations in Small Tidal Inlets, 4th Queensland Coastal Conference, Townsville, Australia, October 2013b.

Shaeri, S., Tomlinson, R. B., Etemad-Shahidi, A., Strauss, D., and Hunt, S.: Field Measurement for Investigating the Dynamics of Currumbin Creek Entrances, J. Coast. Res., Special Issue No. 65, 1212-1217, 2013c.

Shaeri, S., Tomlinson, R. B., Etemad-Shahidi, A., and Strauss, D.: 'Spatial Changes of Beach Profiles for a Small Tidal Inlet (Currumbin Creek, Australia)', Paper submitted to 5th International Symposium on Hydraulic Structures (ISHS2014), Brisbane, Australia, 2014. 